\title{
DETERMINACION DE LA CONCENTRACIÓN DE INOCULO Y TIEMPO DE FERMENTACION, UTILIZANDO MICROBIOTA DE LOS GRANOS DE KEFIR COMO AGENTE BIOLÓGICO Y SUERO DE LECHE COMO SUSTRATO
}

\author{
Determination of the concentration of inoculo and time of fermentation, utilizing \\ microbiota of the kefir grains as biological agent and serum of milk as substrate
}

\author{
Humberto F. Arévalo Ortiz y Gladys C. Arias Arroyo \\ Laboratorio de Bromatología. Facultad de Farmacia y Bioquímica. Universidad Nacional Mayor de San \\ Marcos
}

\begin{abstract}
RESUMEN
Se determinó simultáneamente el tiempo de fermentación y la concentración de inóculo requeridos, obteniendo tanto el tiempo de fermentación como la concentración de inóculo óptimos, ya que el objetivo de este estudio fue determinar el menor tiempo de fermentación con un máximo rendimiento de biomasa. Se utilizó la microbiota de los Granos de Kefir como agente biológico, el cual es una mezcla simbiótica de bacterias y levaduras. Las concentraciones que se emplearon de inóculo fueron de $2 \%, 3 \%, 4 \%, 5 \%, 6 \%, 7 \%$ y $8 \%$. También se determinó los valores extremos de $\mathrm{pH}$, densidad y contenido de azúcares totales que se alcanzaron en los medios de cultivo, para así poder determinar el punto final de la fermentación. Los resultados indicaron que la concentración de inóculo óptimo corresponde a $4 \%$ el mismo que corresponde a un tiempo de fermentación óptimo de 48 horas.
\end{abstract}

Palabras clave: Granos de Kefir, fermentación, inóculo, biomasa.

\section{SUMMARY}

The time of fermentation was determined simultaneously and the concentration of the inocule required, obtaining so much the time of fermentation as the concentration of the inocule, because this estudy's objetive was to determine the smaller time of fermentation with a maximum yield of biomass. Microbiota was used of Grains of Kefir like biological agent, as it is a mixture symbiotic of bacteria and yeasts. The concentrations that were used of the inocule were of $2 \%, 3 \%, 4 \%, 5 \%$, $6 \%, 7 \%$ and $8 \%$. Also one determined the extreme values of $\mathrm{pH}$, density and content of sugars totals that were reached in average of culture, thus to be able to determine full stop of the fermentation. The results indicated that the concentration of the inocule optimal corresponds to $4 \%$ the same that corresponds to optimal time of fermentation of 48 hours.

Keywords: Grains of Kefir, fermentation, I inoculate, biomass.

\section{INTRODUCCION}

Para la producción rentable de biomasa dos variables son de suma importancia: el tiempo de fermentación y la concentración de inóculo al inicio de la fermentación. Respecto al primero, lo que se quiere es que el tiempo de fermentación sea el mínimo posible, pues si este se reduce, se aumenta la productividad.

En cuanto a la concentración de inóculo al inicio de la fermentación, este debe ser el adecuado para así optimizar la producción de biomasa, ya que si la concentración de inóculo es grande, se pierde sustrato debido a una competición exagerada, entre microorganismos que genera muerte celular y exceso de calor. Por otro lado, si la concentración de inóculo es baja, se corre el riesgo de contaminación por microorganismos indeseables, además del incremento en el tiempo de fermentación que disminuye la productividad.

El suero de leche o lactosuero es un subproducto de la industria quesera, de alta calidad nutritiva, que además de agua, contiene lactosa, proteínas,

A quien debe dirigirse la correspondencia. E-mail: ariasarroyo@gmail.com 
minerales y otros compuestos menores disueltos (1). Su composición varía dependiendo de las características de la leche y de las condiciones de la elaboración del queso del cual procede (2). Así pues, el suero es utilizado como sustrato ideal para microorganismos que requieren aminoácidos y son capaces de hidrolizar proteínas (3).

La microbiota de los Granos de Kefir, que en su gran mayoría es una mezcla simbiótica de bacterias lácticas y algunas levaduras que en conjunto se asemejan a diminutas coliflores $(4,5)$, parece ser un buen agente biológico para el presente estudio, ya que metaboliza la lactosa presente en el suero de leche $(3,6,7,8)$; pero también se conoce que pueden fermentar otros tipos de azúcares, dado que los Granos de Kefir esta constituido en un $65-80 \%$, por lactobacilos y el $20-35 \%$ restante, por lactococos, estreptococos y levaduras. $(9,10,11)$.

El objetivo trazado en el presente estudio es determinar la concentración del inóculo y el tiempo de fermentación óptimos, utilizando la microbiota de los Granos de Kefir, como agente biológico y el suero de leche como sustrato.

\section{MATERIAL Y METODOS}

\section{Agente biológico}

Microbiota de los Granos de Kefir provenientes de cuatro casas naturistas de la ciudad de Lima.

\section{Sustrato}

Suero de queso dulce proporcionado por la Empresa VIGOR S.A.

\section{Medio de cultivo patrón}

Como medio de cultivo patrón se utilizó leche fresca pasteurizada, $100 \%$ natural, LA MOLINA (B) proveniente del establo de la Universidad Nacional Agraria La Molina y certificada por SENASA.

\section{Recolección del agente biológico}

Se recolectó cuatro muestras de Granos de Kefir de cuatro casas naturistas de la ciudad de Lima. Se tomó $10 \mathrm{~g}$ de cada muestra y se procedió a juntarlas, de tal manera que pasaron a ser una sola muestra de $40 \mathrm{~g}$.
Crecimiento y control del iniciador o starter de la microbiota de los Granos de Kefir

Los $40 \mathrm{~g}$ de muestra inicial de los Granos de Kefir, se cultivaron en leche, a temperatura ambiente (entre $19^{\circ} \mathrm{C}$ y $26^{\circ} \mathrm{C}$ ), iniciando con una concentración de $5 \%$ de agente biológico respecto al medio de cultivo, tal como lo recomienda Sasaki (4) y cambiando el medio de cultivo cada 24 horas; pero siempre reiniciando el proceso con una concentración de $5 \%$ de agente biológico respecto al medio de cultivo hasta obtener unos $100 \mathrm{~g}$ de agente biológico, de tal manera que se pudiera contar con una fuente de microbiota de los Granos de Kefir, de forma homogénea y permanente para los ensayos respectivos.

\section{Preparación del inóculo}

Una vez obtenido los $100 \mathrm{~g}$ o más de cultivo iniciador o starter, los Granos de Kefir fueron retirados del medio de cultivo (leche) después de haber cumplido un periodo de 24 horas de fermentación. Acto seguido estos granos fueron lavados con agua por tres veces y se dejaron escurrir en un colador, con malla No. 35 ASTM, por espacio de 20 minutos. Los Granos de Kefir así obtenidos fueron los que se utilizaron como inóculos.

\section{Fermentación}

Se utilizó 7 matraces conteniendo $200 \mathrm{ml}$ de suero de leche e inóculo (Granos de Kefir), cuyas concentraciones fueron de $2 \%, 3 \%, 4 \%$ y así sucesivamente hasta llegar hasta $8 \%$. Se inició la fermentación con agitación moderada cada 12 horas, al mismo tiempo que se controló $\mathrm{pH}$, densidad del medio de cultivo y, debido a que hay hidrólisis de la lactosa en glucosa y galactosa durante el proceso de fermentación, también se cuantificó azúcares totales. Se continuó con la fermentación hasta que los valores de $\mathrm{pH}$, densidad del medio de cultivo y contenido de azúcares totales, tendieron a ser constantes. Al final de la fermentación se tomó datos del peso húmedo y peso seco de biomasa obtenidos de cada tratamiento, con el propósito de determinar el porcentaje de incremento de biomasa en cada caso. La prueba fue repetida por tres veces y se tomó los valores promedios.

Finalmente, se preparó tres matraces con una concentración de inóculo de $8 \%$ y se dejaron 
Determinacion de la concentración de inoculo y tiempo de fermentacion, utilizando microbiota de los Granos de Kefir como agente biológico y suero de leche como sustrato

fermentar, hasta determinar el $\mathrm{pH}$ mas bajo posible que alcanza la fermentación de suero de leche con los Granos de Kefir como agente biológico. Se procedió del mismo modo para la densidad y azúcares totales.

Se evaluó el valor de $\mathrm{pH}$ utilizando el método potenciométrico de Egan $\mathrm{H}$., la densidad el método gravimétrico y azucares reductores totales con el método volumétrico de Lane y Eynon de la AOAC, 1997.

\section{RESULTADOS}

Los promedios de variación del $\mathrm{pH}$, densidad se dan en las tablas 1 y 2 respectivamente y de los resultados de densidad, $\mathrm{pH}$ y azúcares reductores llevados al extremo mediante la fermentación con $8 \%$ de inóculo, hasta valores constantes de dichas variables se dan en las figuras 3 y 4 .

La concentración de azúcares reductores totales después de 48 horas de fermentación se observa en la figura 1. En la tabla 3 se muestra los incrementos de biomasa en porcentaje, tanto húmedo como seco y en la figura 2 se muestra el incremento en porcentaje de biomasa seca.

Tabla 1.

Promedios de la variación del $\mathrm{pH}$ durante el proceso de fermentación respecto a la concentración de inóculo.

\begin{tabular}{|c|c|c|c|c|c|c|c|}
\cline { 2 - 8 } \multicolumn{1}{c|}{} & \multicolumn{7}{c|}{ pH } \\
\hline Concentración de inóculo (\%) & $\mathbf{2}$ & $\mathbf{3}$ & $\mathbf{4}$ & $\mathbf{5}$ & $\mathbf{6}$ & $\mathbf{7}$ & $\mathbf{8}$ \\
\hline Tiempo (Horas) & & & & & & & \\
\hline 0 & 6,42 & 6,42 & 6,42 & 6,42 & 6,42 & 6,42 & 6,42 \\
\hline 12 & 4,54 & 4,38 & 4,19 & 4,13 & 4,05 & 3,99 & 3,94 \\
\hline 24 & 4,14 & 3,94 & 3,77 & 3,68 & 3,57 & 3,50 & 3,45 \\
\hline 36 & 4,00 & 3,71 & 3,55 & 3,50 & 3,46 & 3,38 & 3,35 \\
\hline 48 & 3,85 & 3,56 & 3,43 & 3,39 & 3,37 & 3,36 & 3,35 \\
\hline
\end{tabular}

Tabla 2.

Promedios de variación de la densidad durante el proceso de fermentación, respecto a la concentración de inóculo.

\begin{tabular}{|c|c|c|c|c|c|c|c|}
\cline { 2 - 8 } \multicolumn{1}{c|}{} & \multicolumn{7}{c|}{ Densidad (g/ml) } \\
\hline Concentraciónde inóculo (\%) & 2 & 3 & 4 & 5 & 6 & 7 & 8 \\
\hline Tiempo (Horas) & & & & & & & \\
\hline 0 & 1,0234 & 1,0234 & 1,0234 & 1,0234 & 1,0234 & 1,0234 & 1,0234 \\
\hline 12 & 1,0224 & 1,0210 & 1,0191 & 1,0185 & 1,0174 & 1,0167 & 1,0163 \\
\hline 24 & 1,0207 & 1,0180 & 1,0153 & 1,0150 & 1,0147 & 1,0143 & 1,0141 \\
\hline 36 & 1,0191 & 1,0170 & 1,0140 & 1,0139 & 1,0137 & 1,0135 & 1,0135 \\
\hline 48 & 1,0177 & 1,0146 & 1,0135 & 1,0134 & 1,0133 & 1,0132 & 1,0132 \\
\hline
\end{tabular}


Humberto F. Arévalo Ortiz y Gladys C. Arias Arroyo

Figura 1.

Porcentaje de azucares totales que queda en el sustrato después de 48 horas de fermentación, respecto a la concentración de inóculo.

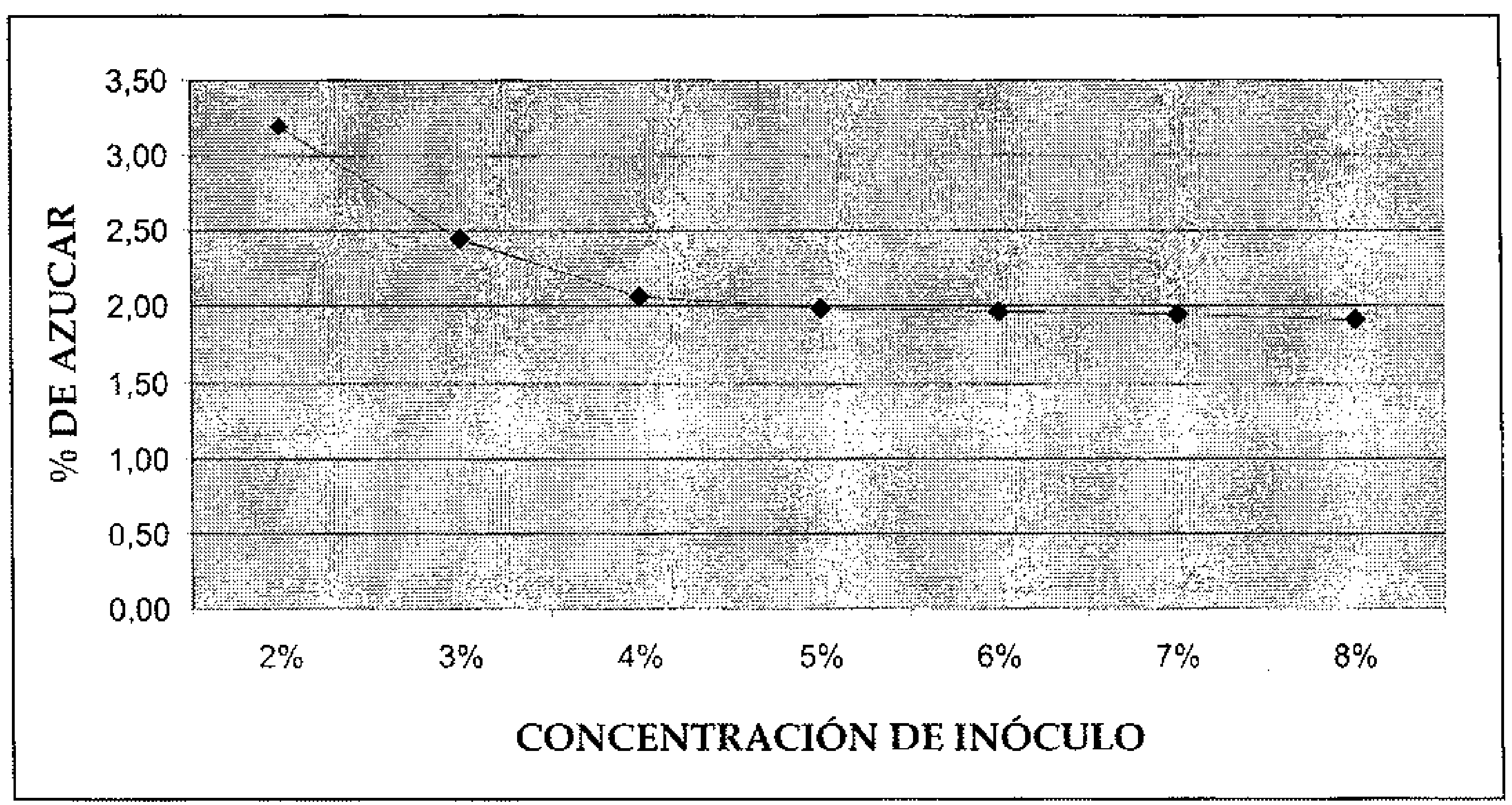

Tabla 3.

Promedios de incremento de biomasa húmeda y seca después de 48 horas de fermentación respecto a la concentración de inóculo

\begin{tabular}{|l|c|c|c|c|c|c|c|}
\cline { 2 - 8 } \multicolumn{1}{c|}{} & \multicolumn{7}{c|}{ Biomasa } \\
\hline Concentraciónde inóculo (\%) & $\mathbf{2}$ & $\mathbf{3}$ & $\mathbf{4}$ & $\mathbf{5}$ & $\mathbf{6}$ & $\mathbf{7}$ & $\mathbf{8}$ \\
\hline Peso húmedo obtenido (g) & 49,616 & 76,432 & 106,146 & 130,691 & 151,767 & 171,210 & 188,022 \\
\hline Peso seco obtenido (g) & 0,5516 & 0,8495 & 11,746 & 14,523 & 16,875 & 19,032 & 20,899 \\
\hline Incremento de biomasa humeda (g) & 0,9616 & 16,432 & 26,146 & 30,691 & 31,767 & 31,210 & 28,022 \\
\hline Incremento de biomasa seca (g) & 0,1069 & 0,1827 & 0,2907 & 0,3412 & 0,3531 & 0,3470 & 0,3115 \\
\hline Incremento de biomasa humeda (\%) & 240,408 & 273,871 & 326,830 & 306,913 & 264,723 & 222,926 & 175,136 \\
\hline Incremento de biomasa seca (\%) & 240,535 & 273,650 & 320,722 & 306,401 & 264,973 & 222,851 & 174,961 \\
\hline
\end{tabular}


Determinacion de la concentración de inoculo y tiempo de fermentacion, utilizando microbiota de los Granos de Kefir como agente biológico y suero de leche como sustrato

Figura 2.

Incremento en porcentaje de biomasa seca, después de 48 horas de fermentación, respecto a la concentración de inóculo.

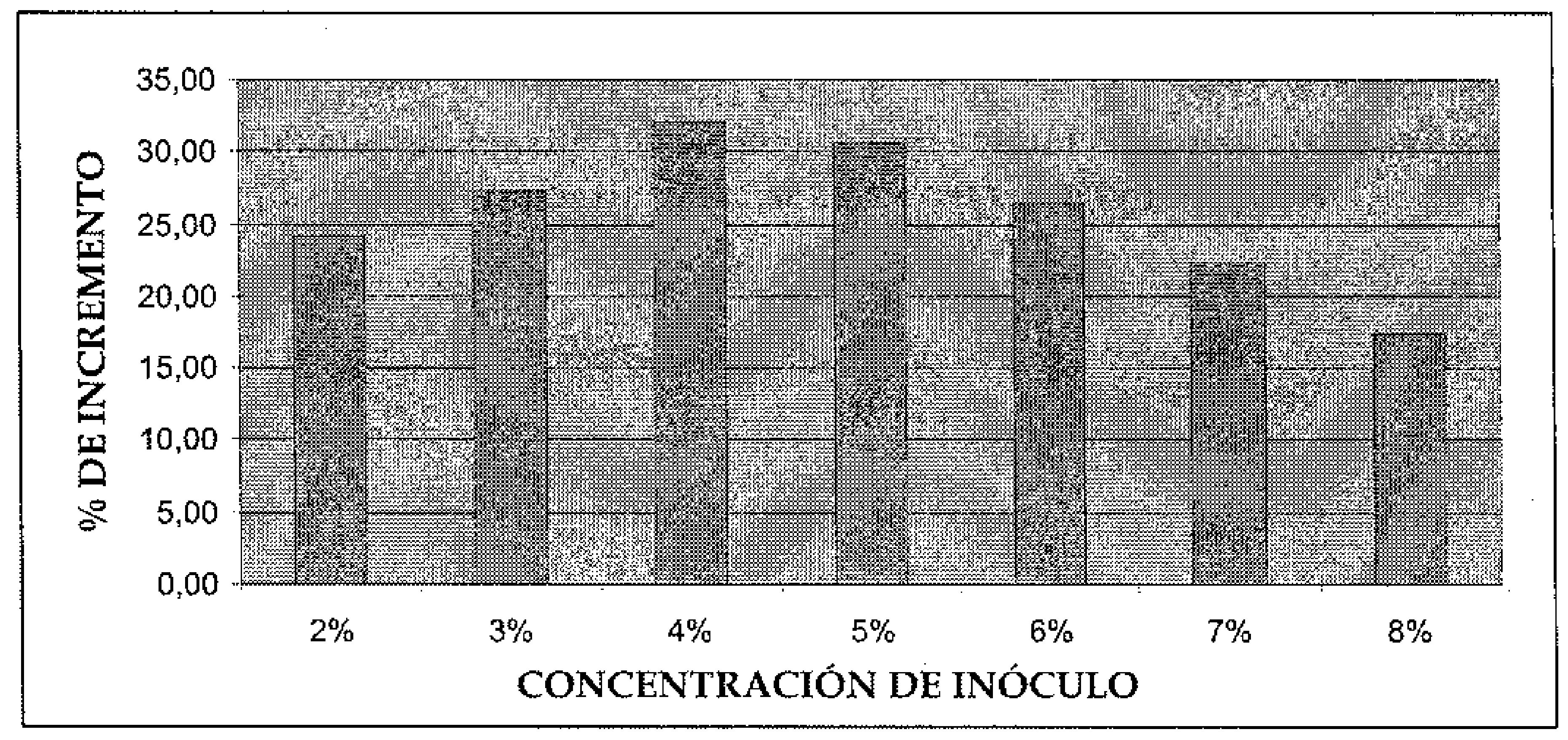

Figura 3.

Densidad llevada hasta valores constantes con $8 \%$ de inóculo

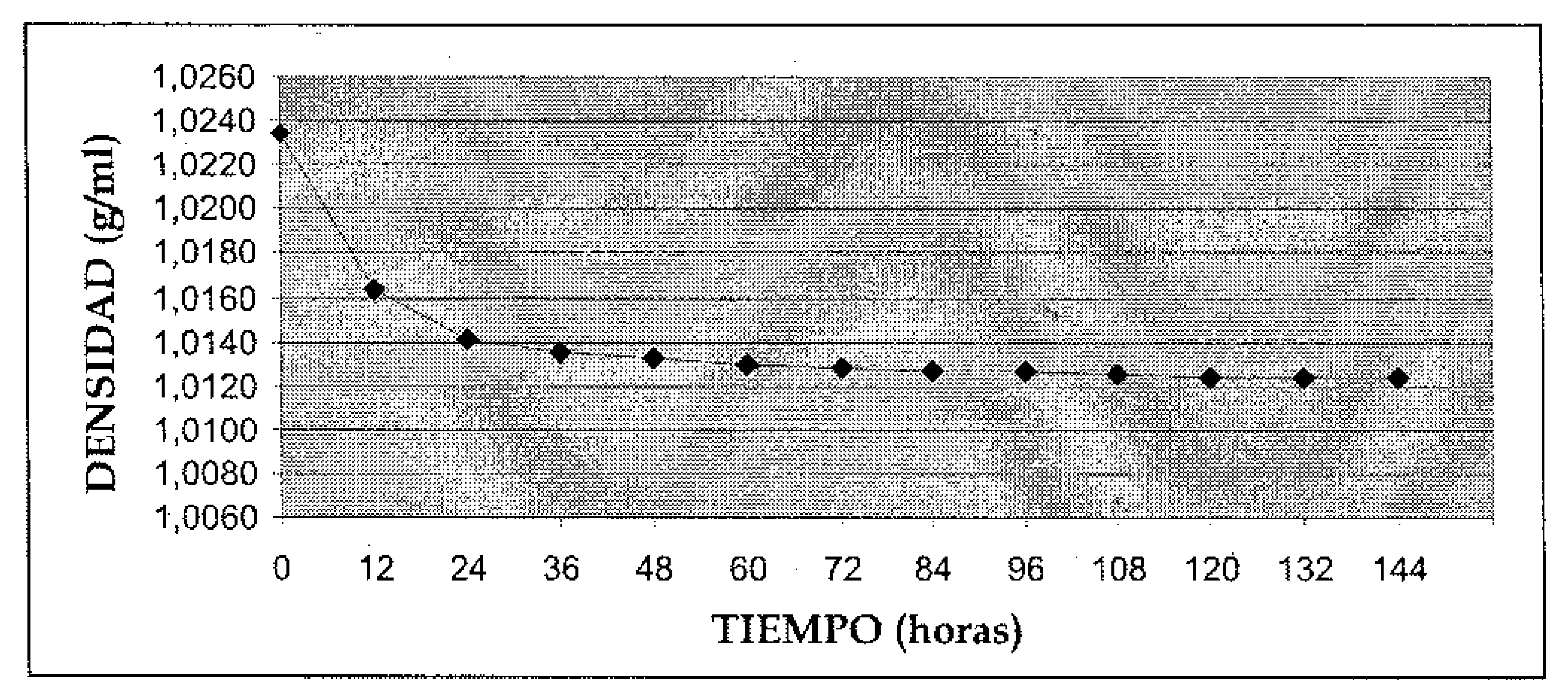

Figura 4.

pH y porcentaje de Azúcares Totales Remanentes (ATR) llevados hasta valores constantes con $8 \%$ de inóculo.

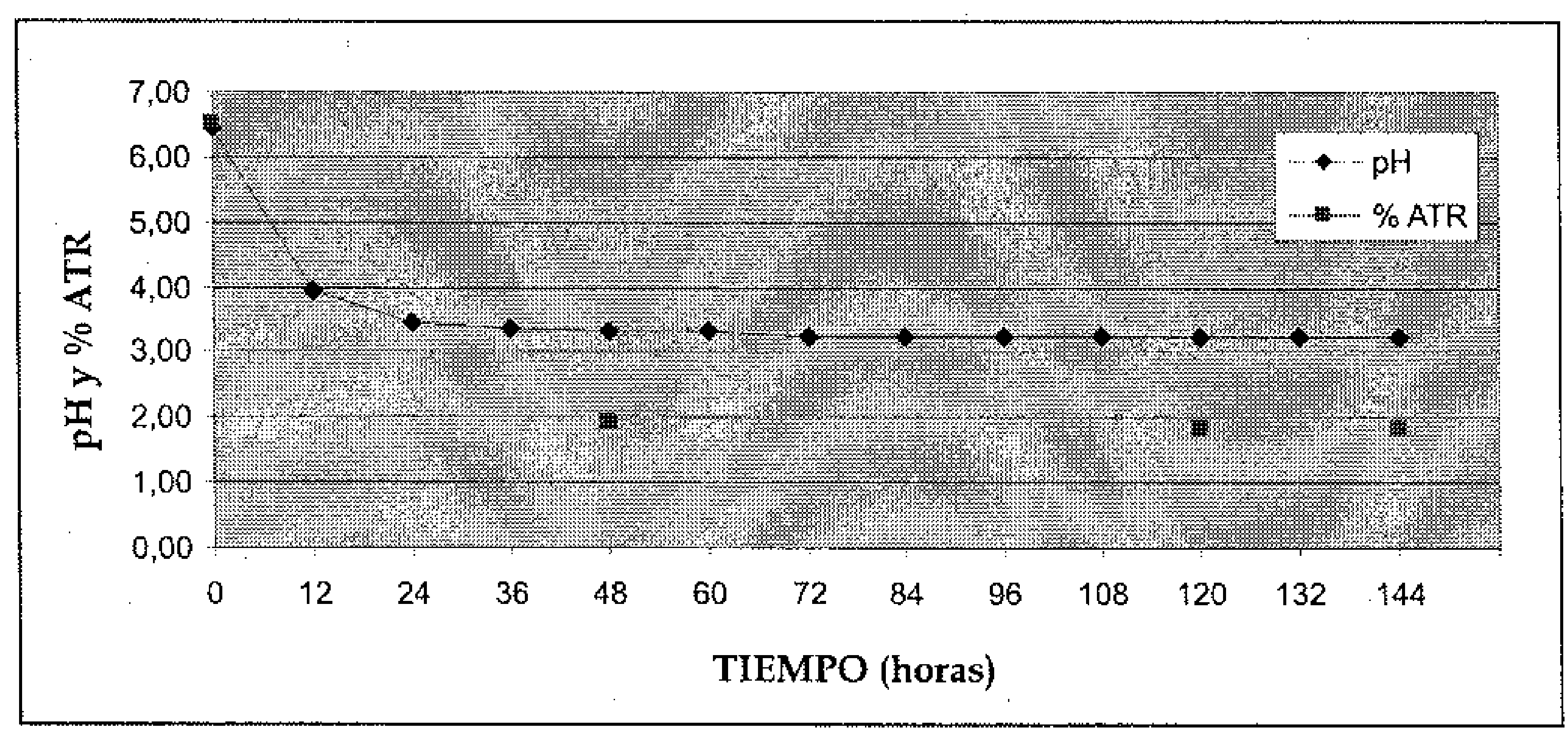




\section{DISCUSION}

En cuanto al $p H$, tal como se observa en la tabla 1 se puede ver que éste cae rápidamente en las 12 primeras horas de fermentación y que esta tendencia disminuye gradualmente a medida que transcurre el tiempo de fermentación. Esto es bastante evidente en el medio con $8 \%$ de inóculo inicial, tanto así que los valores de $p H$ son semejantes a las 36 y 48 horas de fermentación, con un valor de 3,35. Además se observa que cuanto mayor es la concentración inicial de inóculo, el pH baja más rápido y en mayor grado. Esto es obvio, dado la formación de ácido láctico y dióxido de Carbono en mayor cantidad (entre otros) y a mayor velocidad, puesto que alcanza rápidamente condiciones óptimas de $p H$ para el proceso de fermentación $(3,6,7,8)$. En el otro extremo, cuando la concentración de inóculo es $2 \%$, la tendencia anteriormente mencionada ocurre, pero en mucho menor grado, tanto así que a las 48 horas de fermentación la diferencia de valores de $p H$ de los medios de cultivo, entre el correspondiente al $2 \%$ y $8 \%$ de inóculo es de 50 centésimas de $p H$. De acuerdo a los resultados de $p H$, se observa que el valor mínimo de $p H$ que alcanza el medio de cultivo con un inóculo inicial de $2 \%$ después de 48 horas de fermentación es 3,85.

Respecto a la densidad, el análisis es muy semejante al anterior, aunque existen algunas diferencias que se resaltan a continuación. Como se puede ver en la tabla 2, cuando la concentración inicial de inóculo es de $2 \%$, la disminución de la densidad es gradual; pero cuando el inóculo es $8 \%$, la disminución de la densidad es rápido en las 24 primeras horas y tiende a estabilizarse en las horas siguientes.
El análisis realizado para la densidad se corrobora con los datos de la figura 1, pues se observa que después de 48 horas de fermentación el consumo de azúcar se estabiliza a partir de una concentración de inoculo de $4 \%$. Se desprende que la mejor concentración inicial de inoculo se encuentra entre $4 \%$ y $5 \%$ para 48 horas de fermentación.

En cuanto al incremento de biomasa, reflejados en la tabla 3 y figura 2, se observa que el mejor inóculo inicial es el que corresponde a una concentración de $4 \%$, pues a esta concentración y al cabo de 48 horas de fermentación, el incremento de porcentaje de biomasa es el más alto y ligeramente superior al $32 \%$. Esto se debe a que por debajo de $4 \%$ de concentración de inóculo, 48 horas de fermentación es tiempo insuficiente para consumir todo el sustrato disponible o posible, y por encima de $4 \%$ de concentración de inóculo, al cabo de 48 horas de fermentación la relación biomasa producida/sustrato consumido, no es la óptima, pues se observa que a mayor concentración de inóculo, el porcentaje de incremento de biomasa es menor, aun cuando la cantidad de biomasa que se genera es mayor. Se puede ver en la Tabla 3, que la cantidad de biomasa se incrementa en mayor cantidad para el inóculo de $6 \%$.

Concluyendo se puede afirmar que para 48 horas de fermentación, la mejor concentración de inóculo fue de $4 \%$; es decir 8 g de microbiota de los Granos de Kefir para un volumen de $200 \mathrm{ml}$ de suero de leche como sustrato. Por otro lado se puede decir que este procedimiento y análisis se pueden realizar en otros casos en donde la optimización simultánea de estas dos variables sea pertinente. 
Determinacion de la concentración de inoculo y tiempo de fermentacion, utilizando microbiota de los Granos de Kefir como agente biológico y suero de leche como sustrato

\section{REFERENCIAS BIBLIOGRÁFICAS}

1. Potter N. 1978. La Ciencia de los Alimentos. México: Editorial Harla. p. 413.

2. Oria A R. 1991. Ciencia y tecnología de la Leche. Principios y Aplicaciones. Zaragoza: Editorial Acribia S.A. p. 88-90, 275-282.

3. Garcia et. al. 1993. Biotecnología Alimentaria. México D.F.: Editorial Limusa Noriega Editores. p. 178, 197-204, 210-212, 217-222.

4. Sasaki T D. 1995. Elaboración de Kefir. Tesis para optar el título de Ingeniero en Industrias Alimentarias. Facultad de Industrias Alimentarias de la Universidad Nacional Agraria La Molina. Lima. p. 32, 33, 34, 38-40.

5. Bourgeois C M, Larpent J P. 1994. Microbiología Alimentaria. Volumen 2. Fermentaciones Alimentarias. Zaragoza: Editorial Acribia S.A. p. 8-14, 221,222.

6. Marshall V M. 1986.The microflora and production of Fermented Milks, Progress in Industrial Microbiology; 23: 1-44.
7. Tamine A Y y Robinson R K. 1988. Fermented Milks and their Future Trends. Part II. Technological Aspects. Journal of Dairy Research. Published online by Cambridge University; 55: 281-307.

8. Vedamuthu E R. 1982. Fermented Milks, Economic Microbiology. Vol. 7. Fermented Foods. Londres. p. 199-225.

9. Robinson, R.K. 2003. Microbiología Lactológica. Volumen I. Microbiología de la leche. Zaaragoza: Editorial Acribia S.A. p. 48-49, 55-57, 62-64.

10. Collins C H y Lyne P M. 1989. Métodos Microbiológicos. 5ta. Edición. Zaragoza: Editorial Acribia S.A. p. 417-419, 477, 478.

11. Ralph E. 2000. Tecnología de los Productos Lácteos. Zaragoza: Editorial Acribia. S.A. p. 151.

12. Owen P W. 1991. Biotecnología de la Fermentación. Principios, procesos y productos. Zaragoza: Editorial Acribia S.A. p. 111 - 131. 